\title{
Environmental degradation at Lake Urmia (Iran): exploring the causes and their impacts on rural livelihoods
}

\author{
Matthias Schmidt $\cdot$ Robert Gonda $\cdot$ Sebastian Transiskus
}

Published online: 28 March 2020

(C) The Author(s) 2020

\begin{abstract}
During the last 20 years, Lake Urmia, once recognised as one of the largest hypersaline lakes on the planet, has suffered from severe environmental degradation. As a result of climate change and human activities, the lake has been largely desiccated. Previous work around the unfolding environmental disaster mainly focused on Lake Urmia's water regime, water level fluctuations, crisis causes and possible actions to revive its fortunes. However, there has been little discussion on the prevailing socioeconomic consequences for rural livelihoods affected by the disaster. This paper investigates the impacts of the desiccation on rural households and analyses the occurrence and different forms of local villagers' coping strategies. We present the findings of field research in the region, whereby open and semistructured interviews, with both regional experts from
\end{abstract}

\footnotetext{
M. Schmidt $(\bowtie) \cdot$ R. Gonda $\cdot$ S. Transiskus Institute of Geography, University of Augsburg, Alter Postweg 118, 86159 Augsburg, Germany

e-mail: schmidt@geo.uni-augsburg.de

URL: https://www.uni-augsburg.de/de/fakultaet/fai/geo/ prof/geohum/geohum-team/m-schmidt/

R. Gonda

e-mail: robert.gonda@geo.uni-augsburg.de URL: https://www.uni-augsburg.de/de/fakultaet/fai/geo/ prof/geohum/geohum-team/r-gonda/

S. Transiskus

e-mail: sebastian.transiskus@geo.uni-augsburg.de URL: https://www.uni-augsburg.de/de/fakultaet/fai/geo/ prof/geohum/geohum-team/s-transiskus/
}

different institutions and local residents, were conducted. Evidence from this study suggests that rural communities near the lake are considerably dependent on the lake basin's ecosystem services, such as water availability, clean air, soil and local climate regulation-all of which are heavily threatened by progressive environmental degradation. In particular, tourism decline and losses in agriculture have already led to emigration to larger cities, presenting challenges for both rural and urban infrastructures. Overall, the vulnerability of rural households to the crisis was found to be high for reasons such as poverty, lack of income alternatives and a lack of institutional mitigation and adaptation policies.

Keywords Lake Urmia - Slow-onset environmental change - Water management · Vulnerability · Environmental migration · Iran

\section{Introduction}

Climate-related disasters are mainly associated with sudden events such as forest fires, floods or hurricanes. Such events often result in the loss of lives and habitats, and responses are usually managed at regional or even national levels through emergency management plans. Sea level rises, increasing temperatures, ocean acidification, glacial retreat, land degradation, loss of biodiversity or desertification 
occur at a much slower rate and can result, when they have severe negative impacts on humans and infrastructures, in slow-onset disasters (UNFCCC 2012; Alonso 2017; Matias 2017; HRC 2018; IDMC 2018). Although their relatively slow progress provides politicians, entrepreneurs as well as local communities, households and individuals with the opportunity to prepare appropriate responses, the perceived lack of urgency can also be challenging. Moreover, the interactions between longstanding stressors such as natural resource overexploitation with slow-onset events make it difficult to manage all associated risks (Alonso 2017), and failing to address these types of disasters leaves entire communities vulnerable and exposed and can lead to severe socio-economic crises (IDMC 2018).

A recent review of the literature on the topic, conducted by Matias (2017), shows that research is increasingly paying attention to slow-onset events. However, most research has been conducted in regions in the Global North and carried out by researchers from life sciences and physical sciences, whereas social science research has contributed the least. Several studies (Pidgeon and Fischhoff 2011; Victor 2015; Matias 2017) have emphasised the need for social science research on slow-onset events, as "actual impacts that will arise clearly depend on how people will respond" (Yearley 2009).

The desiccation of Lake Urmia (LU), located in north-western Iran, is an example of such a slow-onset disaster. Here, environmental degradation is related not only to climate change, but also to human mismanagement of natural resources. The rapid desiccation of the lake (Fig. 1) and the increasing salinity of the remaining water have already had disastrous effects on the ecosystem's biodiversity, and its continued retreat will eventually lead to the complete elimination of local species and interrupt essential food chains (Karbassi et al. 2010; Dalby and Moussavi 2017).

Experiences from other drying lakes around the world highlight both current and upcoming threats and risks for rural villagers living near such bodies of water. The population around the Aral Sea, for instance, suffered from several acute health problems caused by depletion, dust storms or water contamination. Similar processes have already started at LU, as the parched surface of the lake bed has turned into a salty desert of thousands of square kilometres
(Hassanzadeh et al. 2012; Gholampour et al. 2015; Torabian 2015; Toutakhaneh et al. 2018).

This raises questions in terms of local villagers' vulnerability $^{1}$ and resilience ${ }^{2}$ to the disaster. Not everyone is equally vulnerable to different stages of environmental change, and one's social position or occupation may bolster against the impacts of environmental degradation (Warner et al. 2010). In addition, resilience-building by households or within communities can mitigate many negative outcomes in this regard. The apparent overall decline in economic and social well-being also places emphasis on the issue of past, present and future occurrences and the implications of environmentally-induced migration in the region (Torabian 2015).

Previous work around the unfolding environmental disaster at Lake Urmia has largely focused on its water regime, water level fluctuations, ecological consequences, causes and possible actions to revive the lake (Fathian et al. 2014; Tourian et al. 2015; ULRP 2015; Shadkam et al. 2016; Taravat et al. 2016; Bavil et al. 2018; Ghale et al. 2017; Jeihouni et al. 2017; Sanikhani et al. 2017; Soudi et al. 2017; Taheri et al. 2019), as the need for restoration measures has sparked international attention. However, the manifold consequences of the disaster and their impact on people living in rural settlements around the lake, as well as individual or communal adaptation strategies, have barely been investigated. After reviewing over 200 scientific papers on Lake Urmia, to date only four papers have partly (and superficially) addressed these dimensions (Torabian 2015; Azizpour et al. 2015; Toutakhaneh et al. 2018; Maleki et al. 2018). Indeed, only Maleki et al. (2018) provide a field-based and scientifically sound vulnerability assessment of rural households' actions in terms of environmental change in the basin. In their case study conducted in Shabestar, a city in the province of East Azerbaijan, located east of LU, they found that $87.2 \%$ of 347 households had a medium-to-high level of

\footnotetext{
$\overline{1}$ Vulnerability is seen here as the propensity or predisposition to be adversely affected, and it encompasses a variety of concepts and elements, including sensitivity or susceptibility to harm and lack of capacity to cope and adapt (IPCC 2014).

${ }^{2}$ Resilience can be understood as the capacity of systems to cope with a hazardous event or trend or disturbance, responding or reorganising in ways that maintain their essential function, identity and structure, while also maintaining the capacity for adaptation, learning and transformation (IPCC 2014).
} 

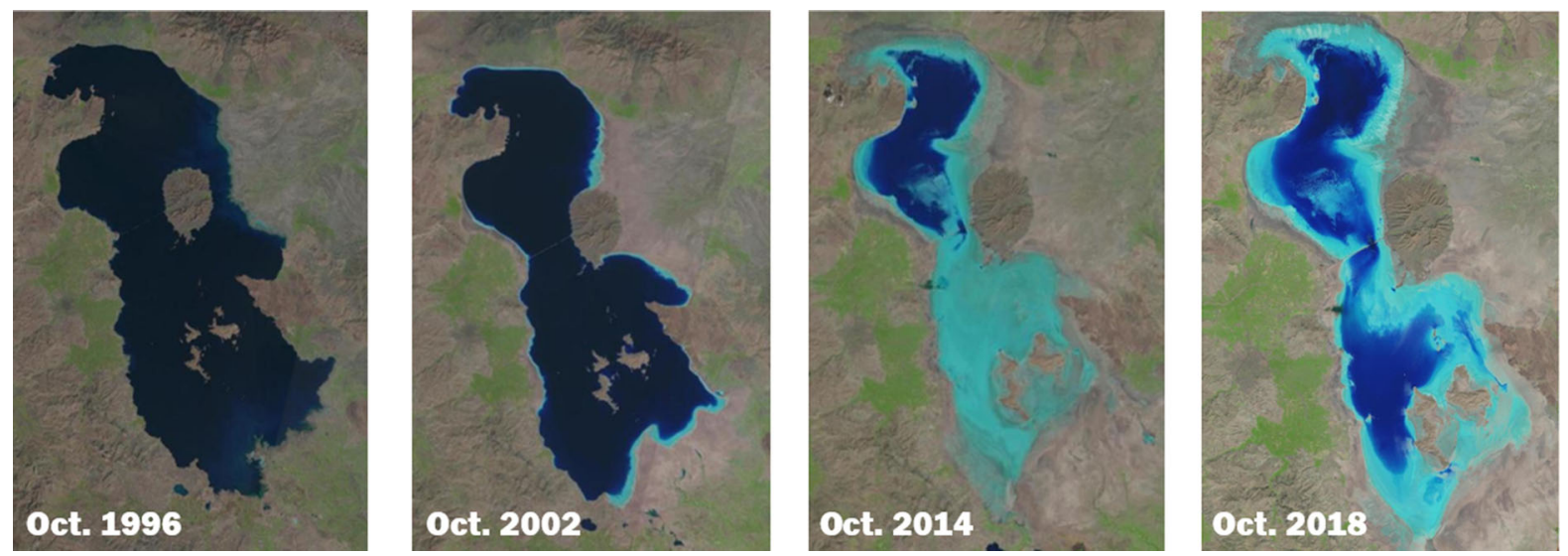

Fig. 1 Temporal changes in the surface area of Lake Urmia, derived from Landsat imagery. Source: USGS 2019

vulnerability to LU's drying, and they concluded that their study "only scratched the surface" and recommended that future work should "examine the coping strategies of villagers" (Maleki et al. 2018).

Against this backdrop, the aim of this article is to analyse the impacts of environmental changes at Lake Urmia on rural livelihoods, and to document different local villagers' adaptation strategies. We do so by discussing the following research questions. What are the socio-ecological and socio-economic consequences of environmental degradation for rural livelihoods? How do villagers perceive and experience environmental change? Who is particularly vulnerable to the disaster? How do people adapt to the environmental disaster?

This paper is divided into three sections. First, we present the latest findings on the major causes of LU's desiccation. A profound understanding of what has caused this problem is a prerequisite for both politicians and households to develop, promote and support adaptation strategies in the context of sustainable water management. Second, this paper adds to the state of research on the prevailing local villagers' social vulnerability and different coping strategies by presenting the findings of empirical fieldwork in the region. Subsequently, we take a closer look at currently proposed actions to save the lake from drying, and finally we discuss our results.

\section{Research area}

The Lake Urmia basin (Fig. 2) is located in northwestern Iran and covers an area of about $52,000 \mathrm{~km}^{2}$. The lake itself lies amid the three provinces of East Azerbaijan, West Azerbaijan and Kurdistan (ULRP 2017; Taheri et al. 2019), and it was once known as one of the largest hypersaline water bodies on Earth. Until recently, the basin fulfilled ecological, social and economic functions for residents in terms of biodiversity, habitat, local climate regulation, agriculture and tourism, and in this respect, LU was declared a Wetland of International Importance by the Ramsar Convention in 1971 and designated a UNESCO Biosphere Reserve in 1976 (UNEP-GEAS 2012).

Over the past two decades, however, the combination of climate change and intense water use has caused a substantially lower water inflow into the terminal lake. As a result, LU's surface area has shrivelled from $5500 \mathrm{~km}^{2}$ in 1995 to around $1661 \mathrm{~km}^{2}$ in November 2018. During the same period, the lake lost over $90 \%$ of its water volume and reduced down to 1 billion cubic metres (Sheikhi 2018), far below its ecological balance ${ }^{3}$ of 14.5 billion cubic metres (ULRP 2015). Accordingly, the water level of the shallow lake is $7 \mathrm{~m}$ lower (Agha Kouchak et al. 2014; Alipour and Olya 2015; Tourian et al. 2015; ULRP 2015; Shadkam et al. 2016; IEW 2018).

\footnotetext{
${ }_{3}$ Ecological balance is defined as the equilibrium between, and harmonious coexistence of, organisms and their environment (OECD 2001).
} 


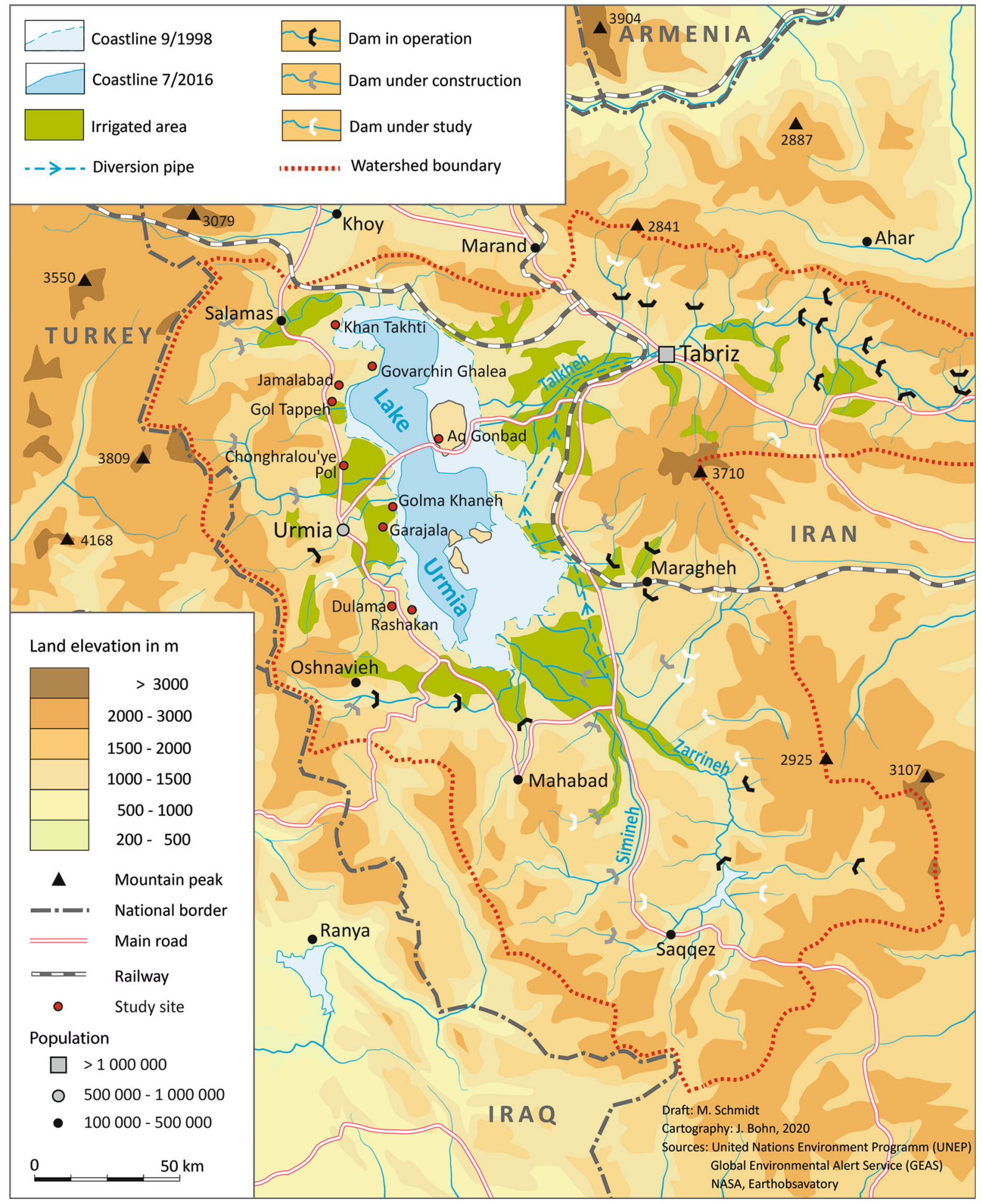

Fig. 2 The water catchment area of the Lake Urmia basin, irrigated area and study sites 
Lately, some reports have argued for a recent recovery (UNEP 2017), but these works have failed to consider short-term climate variability and typically relied on satellite images, which indeed show a substantial growth in LU's surface area compared to its all-time low in 2014 (Fig. 1). In actuality, the total water volume has hardly increased-or even decreased continuously-as demonstrated by Agh (2018), who illustrates how evaporation has led to salt-sedimentation processes, ultimately making the lake shallower. Due to these changes in geomorphology, today a smaller total amount of water is spread over a wider area, leading to false impressions of the lake's real water volume and overall condition (Agh 2018).

The LU basin's semi-arid climate shows considerable seasonal variations in air temperature, generally between 0 and $-20{ }^{\circ} \mathrm{C}$ in winter and up to $40{ }^{\circ} \mathrm{C}$ in summer (Mehrian et al. 2016). Annual precipitation varies between 300 and $400 \mathrm{~mm}, 77 \%$ of which occurs between December and May, while the annual evaporation rate from the lake surface is approximately $1000 \mathrm{~mm}$. Approximately 60 rivers feed permanently or episodically into LU, and almost all of them flow through agricultural, industrial and urban areas before reaching the lake (Sima and Tajrishy 2013; Taravat et al. 2016; Agh 2018).

The lake's basin is home to 5.2 million people, $50 \%$ of which live in East Azerbaijan, 45\% in West Azerbaijan and 5\% in Kurdistan (ULRP 2017). About 1.5 million people in 415,000 households are rated as rural population (Maleki et al. 2018), and they are particularly dependent on resources such as water, soil and crops. Against this backdrop, our research was set up in a way to gain insights regarding the consequences of environmental degradation, social vulnerabilities and local adaptation strategies for the rural population.

\section{Research methods}

Our paper mainly draws on data collected via qualitative open and semi-structured interviews with regional experts from different institutions (i.e. universities, ULRP) and residents in rural areas around LU, all of which were conducted in autumn 2018 and in September 2019. Expert interviews contributed to this research, as they offered specialised knowledge on the most recent environmental degradation processes, water management and restoration measures. However, concentrating on the local population on the micro level is the main focus of this study, since members of this group in particular find themselves confronted with existential risks.

We tried to ensure a certain level of regional diversity in terms of the villages visited, in order to grasp different spatial contexts and to obtain a differentiated picture of the situation. Therefore, we carried out interviews in twelve communities in close proximity to the lake, both in the west and the east of the lake. Although all of the participants were selected randomly from these locations, the authors tried to assure diversity in terms of the interviewed persons' occupation (i.e. farming, tourism, retail trade, etc.), personal assets and socio-cultural context. We saw these factors as necessary prerequisites in order to gain a better understanding of the crisis's consequences on villagers from different localities and with different personal backgrounds. Based on this approach, regions or communities with particularly high vulnerability to the environmental disaster could be identified. Personal details of the interviewed persons were documented where possible, albeit names are not provided in this paper, in order to respect participant privacy.

In accordance with Girtler's (2001) “ero-epic conversation" as an interview method, the randomly selected individuals or groups were instructed in advance about the research interest and the researcher's background. Fundamental to this type of interview is that both the interviewee and the researcher open up and engage in conversation. The fact that researchers also talk about themselves and their own experiences related to the topic creates a relaxed, familiar and personal level of conversation and at the same time encourages the interviewees to tell about themselves. The questions arose from the situation and were not strictly set in advance. Nevertheless, we tried to steer the conversations in certain directions, to cover the following topics:

- Personal perception or experience of consequences resulting from the environmental disaster, local climate change, water scarcity, etc.;

- Household background and vulnerability to the lake's drying and its associated consequences; 
- Access to and use of knowledge related to coping with LU's desiccation and its effects, the ability to reorganise activities or to adapt to environmental degradation;

- The observed role of migration as a coping strategy in the respective village.

The interviews offered valuable insights into the impacts of LU's desiccation and its consequences on individual, household or even community levels. Furthermore, they helped to understand people's knowledge of susceptibility to environmental change and their ability to cope with, recover from or adapt to it accordingly.

Additionally, we used visual observation to provide complementary evidence to the more formalised method of interviewing. This involved taking field notes on local conditions around LU, such as the extent of environmental degradation, the general state of infrastructure, agricultural lands and cultivated crops or overall water availability.

\section{Results}

Causes of Lake Urmia's desiccation

The causes of the enormous water loss of Lake Urmia are manifold and continue to be extensively studied and discussed in the scientific community (Hassanzadeh et al. 2012; Mehrian et al. 2016; Shadkam et al. 2016; Talebi et al. 2016; Khazaei et al. 2019). Generally, the decline is blamed on a combination of climate change and human-induced drivers (Agha Kouchak et al. 2014; Jalili et al. 2016; AlizadehChoobari et al. 2016; Ghale et al. 2017; Arkian et al. 2018; Chaudhari et al. 2018).

Climatic variability and irregular precipitation in the semi-arid area of north-western Iran have always led to significant fluctuations in Lake Urmia water levels, with the last maximum being reached in the mid-1990s (Fathian et al. 2014; Jalili et al. 2016; Taravat et al. 2016). Nevertheless, during the last few decades, a substantial decrease in precipitation, higher air temperatures and persistent drought periods have been recorded (Delju et al. 2013; Razmara et al. 2013; Shadkam et al. 2016; Taravat et al. 2016; Sanikhani et al. 2017; Arkian et al. 2018). Consequently, direct inflow into the lake has diminished while the evaporation rate increased, in turn leading to increased water demand by the agricultural sector (ULRP 2015).

Nonetheless, the speed and rigidity of the current water loss (causing a historical low) cannot be attributed solely to natural causes alone, and in this regard the scientific community mostly agrees that human-induced impacts also played a great role in Lake Urmia's rapid depletion (Zeinoddini et al. 2015; Alizadeh-Choobari et al. 2016; Ouria and Sevinc 2016; Jalili et al. 2016; Talebi et al. 2016; Ghale et al. 2017).

As Lake Urmia is a terminal lake, the increasing amounts of water withdrawn from its feeder rivers, in order to expand agricultural lands, are considered a main contributor of the current crisis. Since the Islamic Revolution of 1979, Iran's population has more than doubled, from 37 million to around 82 million today (Worldbank 2019). This high population growth led to an increasing demand for food and water (Madani 2014) - a situation intensified by the international trade embargo imposed on the country. To satisfy the nation's growing needs, dams, groundwater pumping stations and water diversion pipelines have been constructed in the basin. Particularly, within the last three decades, about 50 large dams have been constructed in the Lake Urmia catchment area (Alizadeh-Choobari et al. 2016; Ouria and Sevinc 2016).

The availability of irrigation water accumulated behind the dams has in turn led to increasing rates of water withdrawal and evaporation, and these water infrastructure developments have not only reduced direct water inflow into the lake, but they also allowed the overall size of the total cultivated area to triple (Mehrian et al. 2016; Dalby and Moussavi 2017). Additionally, many of the previously exclusively rainfed agricultural lands have become irrigated farmland, growing from $3035 \mathrm{~km}^{2}$ in 1984 to $5086 \mathrm{~km}^{2}$ in 2014 , an increase of $67.5 \%$ (Mehrian et al. 2016).

Additionally, cultivation strategies have shifted from subsistence farming to intensive agriculture, leading not only to changed cropping patterns based on more valuable returns, but also to thirstier crops such as sugar beet and apples (Ilhan and Ayboga 2012; Zaman et al. 2016; Dalby and Moussavi 2017). Apples especially are produced in large quantities around LU, which has led to an oversupply of product for food markets and processing industries in the area. As observed during our field trips, huge piles of partly rotting apples were sold by fruit merchants at the 
roadsides, seemingly unsuitable for any further utilisation. Nonetheless, many farmers still build their existence on the production of apples, even though it is barely profitable. However, switching to another agricultural product can be costly and risky. Many farmers resile from changing their crops, which was underlined by one interview partner saying "I' $d$ rather cut my arm than my tree".

The increase in surface water use has gone together with an aggressive underground water withdrawal campaign, with tens of thousands of deep-wells being drilled. Presently, there are almost 90,000 wells in the LU basin, around $50 \%$ of which have been drilled illegally (ULRP 2015). Currently, roughly $70 \%$ of renewable water resources in the basin are consumed, with the agricultural sector accounting for a minimum of $90 \%$ of the total water use (Madani 2014; ULRP 2015). Accordingly, a large amount of water consumed by agriculture is not being discharged into Lake Urmia. In fact, according to ULRP (2015), during the past two decades the water runoff feeding the lake has decreased by $50 \%$ in comparison to its long-term recorded data, amounting to 30 billion cubic metres of "lost water."

Furthermore, two construction projects have negatively affected the water ecology of the lake. The first was the construction of a $15 \mathrm{~km}$-long causeway across Lake Urmia, which opened in 2000 and established a direct route between the cities of Tabriz and Urmia. It divides the lake into two areas, which are only connected by a small $1.25 \mathrm{~km}$ opening in the embankment. Hence, the circulation or water exchange between the northern and southern parts of the lake are massively hindered (Marjani and Jamali 2014; Zeinoddini et al. 2015). As a result, sedimentation behaviour changes and the water heats up faster, which in turn leads to higher evaporation (Marjani and Jamali 2014).

The second construction project concerns a water pipeline, which has been channelling around 3 billion cubic metres of water annually from the Zarrineh River into the urban area of Tabriz since 1999, thereby reducing the amount of water coming from one of the most important inflows into the endorheic lake (Khalyani et al. 2014; Alizadeh-Choobari et al. 2016). In this context, the disproportionately high demand for water in the growing urban agglomerations of Tabriz (about 2.2 million inhabitants) and Urmia (about 0.7 million inhabitants) is often cited as a major cause of increased water consumption. Although the water used in cities is not necessarily lost completely — as some of it returns via the sewage system or diffusing otherwise-it returns to the water cycle in greatly decreased quality (Schmidt 2018).

Besides, and hardly discussed in the scientific community, the construction boom of luxurious weekend houses on the outskirts of urban agglomerations and rural areas is also associated with high water consumption. In many places, wealthy townspeople transform cropland, pasture and fallow land into built-up areas by setting up weekend cottages, which usually have large, water-hungry ornamental gardens (Sigaroodi and Ebrahimi 2010; Schmidt 2018).

Impacts of environmental degradation on rural livelihoods

"I am afraid that we will suffer the same fate as the Aral Sea" (elderly man, Garajala, 1 October 2018).

Experiences from other drying lakes around the world act as portents to the hazardous consequences affecting Lake Urmia. However, although the parallels between LU and the Aral Sea are evident, the pace of desiccation, the number of affected people and the political and socio-economic circumstances are different. Most notably, the area around Lake Urmia is populated more densely, putting 5.2 million people at risk (ULRP 2017).

Since almost three-quarters of the lake has desiccated, a salt-covered lakebed of thousands of square kilometres has been left behind, with the consequence of increased wind erosion. Hence, the occurrence of salty dust storms has increased in recent years, threatening surrounding farmlands, livestock and livelihoods with salt deposits and salt particles in the air (Garousi et al. 2013). In this context, there is growing evidence that aerosols are emitted not only from LU's surface, but also from desiccated bordering lands such as dried watercourses and river deltas (Gholampour et al. 2015; Ghale et al. 2017; Mardi et al. 2018).

\section{Health issues}

Saline dust winds, especially in the dry summer months, may transport high concentrations of finegrain saline, alkaline material and other potentially 
toxic components as far as $300 \mathrm{~km}$ (Gholampour et al. 2015). The inhaled toxins and minerals have been linked to an increasing number of health issues such as throat and lung cancer, infant mortality, decreasing life expectancy and increasing child defects in regions adjacent to the lake (Torabian 2015; Anvari and Valaie 2015; Pesyan et al. 2017; Maleki et al. 2018; Mohammadi et al. 2019; Samadi et al. 2019).

"I can barely breathe outside and prefer to stay in the house," an elderly female resident of Golma Khaneh, a small coastal town, admitted to us (4 October 2018). During our fieldwork, we noticed that especially on the eastern side of the lake many people complained about the increasing occurrence of respiratory diseases, which they attributed to the emergence of salt-laden winds. In fact, this observation is consistent with the ULRP's estimates that the more frequent west-east wind direction will increase the pressure on regions on the eastern side of Lake Urmia (ULRP 2015; 2017). To gain a better understanding of the significance of salt storms on people's health, the Universities of Medical Sciences in Tabriz and Urmia have started a comprehensive long-term study of these effects on people residing in the region (Financial Tribune 2017). Mardi (2018) suggests protecting those areas bordering LU by planting vegetation as a useful strategy for emission control.

Moreover, the decline of available water and the increasing amount of contaminated water have caused additional health issues, especially for poor and vulnerable households, whose access to proper nutrition, hygiene and fresh water supply was already low (Torabian 2015). Thus, it is very likely that further depletion of the lake will amplify disease outbreaks and health issues for the local population.

\section{Economic decline}

Environmental degradation hampers economic development and productivity in the region in various ways. First of all, agriculture and livestock production-the most important source of income for villagers in NW Iran-are under pressure. Salt deposits diminish the fertility of soils and cause a decline in rural agricultural incomes, as farmlands, orchards and pastures are damaged and the water demand for leaching salts from the top soils increases (thereby causing water resource contamination).
Further pressure is imposed on the agricultural sector by overall low water availability and quality, due to changes in the regional climate, the overexploitation of groundwater resources and reduced river runoff caused by upstream water extraction (Anvari and Valaie 2015; Azizpour et al. 2015). Actually, the formerly vast expanse of Lake Urmia had a balancing impact on the micro-climate throughout the basin. However, there is evidence that due to its progressive and ongoing desiccation, the daily temperature amplitude has increased, relative humidity has dropped and the annual precipitation regime has changed (Ghalibaf and Moussavi 2014; Azizpour et al. 2015). This corresponds with the effects of overall climate change and the experiences of local farmers. As recounted mournfully by a middle-aged farmer from Chonghralou'ye Pol (1 October 2018), "The summers over the past years have been hotter and drier than ever. At the same time, we suffer from crop losses because of heavy rains in spring."

Water quality is worsening throughout the basin because of fertiliser and pesticide deposits, as well as the overuse of local groundwater, leading to saltwater intrusions into aquifers (Dalby and Moussavi 2017). A resident of Aq Gonbad explained the farmers' situation thus (3 October 2018): "The water is salty and dirty, and there is a lot of salt in the air. Our cattle are having an increasing number of stillbirths."

Evidently, the sustainability of existing farming systems and livelihoods is under threat, as water shortages and contamination are already critical today and are likely to become more severe in the future. Interviewed local farmers perceived this disaster just as critically as the literature indicates: "Agriculture is dead. We don't know if we can survive another year" (Male elder, Garajala, 2 October 2018).

Tourism was another important source of income for the local population near the formerly pleasant shoreline of Lake Urmia. New tourist resorts had been constructed in close proximity to the lake up to the early 2000s, when a tipping point was reached and the number of visitors who used to benefit from medicinal mud applications underwent a steady decrease (Torabian 2015). Likewise, tourism-dependent businesses, such as those producing clay for healing purposes, tourist shops and boat rentals, are now no longer viable (Farhudy and Hajilou 2012). 


\section{Migration as an adaptation strategy}

In response to the ongoing environmental disaster, many people around the lake have already left their villages. "Not long ago, 500 people lived in our village, most of them working in tourism. Now, tourism is dead. All younger people have left to find a job in the city," we were told by an elderly resident of Golma Khaneh, a formerly touristic village with beaches and now deserted villas, once known as the lake's main coastal port on the western shore (4 October 2018). Indeed, households that relied on tourism were among the first to be affected by the disaster. As the lake began to shrink, people lost their jobs and the property values of the surrounding lands decreased, thereby creating additional financial problems for many families (Daryani 2019). In need of other income opportunities, many people moved away or shifted to farming, thus increasing the already high pressure on water resources.

However, several farmers also left their home villages in order to adapt to the disaster, which can be blamed on the region's increasing water stress: "Many of my friends who worked in agriculture moved to the city. However, due to the difficult job market, they usually follow simple tasks as day labourers. As for me, I am not prepared for this disaster. I don't know what to do if the wells are completely dry next year," a young farmer told us while showing his sun-burned fields and his dried-up well (Chonghralou'ye Pol, 01 October 2018). In the future, thousands of farmers could lose their economic foundations, which in turn might lead to higher rates of out-migration and an overall decline in rural settlements. A middle-aged resident of Aq Gonbad (03 October 2018) joined us for a walk through his native village, which had long been dominated by agriculture: "In the past, 6,000 people lived in this village, but today there are only 800 left. For every three women in the village, there is only one man left. Almost all men of working age live and work in the city of Urmia. Many people find no jobs, even if they have studied. Others take on simple work after graduation, such as being a bus driver." Many farmers reported that due to crop failures and declining incomes they were forced to sell plots of their agricultural land in order to survive. Other immediate adaptation strategies included deepening or digging new wells, to ensure some form of field irrigation and to maintain drinking water supplies, thereby putting further pressure on water resources. During the interviews, we became aware that a lack of perspective, a lack of any adaptive capacity and general helplessness were no exceptions; in fact, they were very much the norm for many villagers. As a consequence of environmental degradation, migration had become a common adaptation strategy for rural people.

A young man from Golma Kaneh described the process and impacts of emigration from the village as follows (4 October 2018): "Due to a lack of job prospects, the young people left the village first. They went to work in the city and supported their families in the village with money returns." Indeed, if migrating from the adjacent lake areas turns out positively for individuals, remittances can further prompt positive effects for the remaining household members (Warner et al. 2010). Households may choose to send one member to support household livelihoods by transferring remittances. However, our interviewee also pointed out the general lack of good job opportunities and described negative consequences for the villages as follows: "Today, because more and more people have moved away, many schools have closed down and buses are less frequent, as they are not economical anymore."

Institutional restoration measures

In 2013, the Iranian government set up a committee to develop a roadmap and action plan to save Lake Urmia, known as the Urmia Lake Restoration Programme (ULRP). The ULRP implemented 88 projects, with the main goal of restoring the ecological level of the lake-1274 m above sea level—by 2023 (ULRP 2015). As part of the programme, several projects have been set up with international help, most notably in the form of cooperation with the Food and Agriculture Organisation of the United Nations (FAO), the United Nations Development Programme (UNDP) and the Global Environment Facility (GEF) (UNEP 2017). Another example of international collaboration is the 'Restoration of Lake Urmia via local community participation in sustainable agriculture and biodiversity conservation' project, established through the financial support of the Japanese government (CIWP 2016).

Furthermore, additional dam construction initiatives have been put on hold in the meantime. Other 
strategies initiated to save the lake appear to be somewhat short-sighted, as they are focused on symptoms as opposed to causes. For instance, in the last few years, the view has increasingly gained credence that the only solution left to save the lake is water transfer from other rivers or water basins, as reflected in some of the ULRP's project initiatives (Madani 2014; ULRP 2015, 2017).

Currently, water prices are heavily subsidised in Iran, which leaves no incentives for farmers to increase water use efficiency. Furthermore, the government has limited control over groundwater abstraction, as there are huge numbers of illegal wells, highlighting a significant data gap. Current data collected around LU do not include water consumption at the field level, and the limited data that exist are either out of date or deposited in inaccessible archives. Relying only on guesstimates for water consumption or availability is not good enough for Lake Urmia restoration purposes (ULRP 2017). Well depth and pumping capacity are the only limiting factors for groundwater withdrawal. Farmers dig deeper and install larger pumps when the groundwater level drops; however, we were told frequently that the groundwater situation in 2018 was extremely critical, with many wells left completely dry: "I don't need more petroleum and bread. I need water and work" (Male elder, Ghoma Khaneh, 4 October 2018).

Against this backdrop, a major objective of the ULRP is the enforcement of a $40 \%$ reduction in water use in the agricultural sector by revising water management and agricultural techniques over a fiveyear period (ULRP 2015, 2017); indeed, the agricultural sector utilises about $90 \%$ of the water resources in the catchment area (Madani 2014). Apart from the quantity of water used, local farmers seem to mismanage this valuable resource. For example, Mojarrad-Ashnaabad (2013) pointed out that the amounts of rainfall and water resources accessible in the LU basin are higher compared to the required water volume for agriculture, because farmers allocate water according to their cultivation area instead of what is actually required by the crops. At the start of the season, farmers pay a water fee based on predetermined allocation rights, regardless of the actual amount used, and so naturally they consume as much water as possible, even though they might exceed actual crop needs. However, when irrigation water is unavailable, farmers tend to drill wells, whether legal or illegal. In downstream areas, where water is partly even less accessible, farmers pump water from nearby rivers into irrigation channels (ULRP 2015, 2017), and consequently they are the main focal point for water resource management programmes (Valizadeh et al. 2018).

Latest concerns regarding the lake's restoration relate to the lack of funds. According to an Iranian newspaper article from early 2018, about $80 \%$ of restoration projects have been suspended, leaving most revival efforts incomplete. In November 2017, an Iranian Azerbaijani parliamentarian concluded that the Urmia lake issue had been forgotten and "people [were] seeing the death of the lake in front of their eyes, despite the statements made by officials" (Niayesh 2018). In July 2018, officials from West Azerbaijan's Department of Environment announced that some parts of the lake, stretching as far as 500 $\mathrm{km}^{2}$, were beyond restoration and would be reshaped to become a natural park (Tehran Times 2018).

Overall, it seems very unlikely that ULRP will reach its restoration target, although there is no doubt that the environmental and socio-economic costs of the Lake Urmia disaster are very high, as more and more negative consequences throughout the region become visible.

\section{Discussion}

Numerous rural dwellers around Lake Urmia are currently affected by an environmental disaster. They are dependent on resources such as clean potable water, water for irrigation purposes, clean air and fertile soil. During our field research, in which we specifically talked to people with different personal backgrounds and ages, and from different regions around the lake, we became aware that most of them only had limited resources and skills to adapt to the changing environmental conditions. The reasons included poverty and a general lack of prospects. In this context, our findings fall in line with previous findings (Anvari and Valaie 2015; Azizpour et al. 2015; Maleki et al. 2018) and provide further evidence on the interplay between disastrous environmental change, socio-economic consequences and the adaptation strategies of the rural population at Lake Urmia, which are barely investigated in scientific literature. 
During our fieldwork, we recognised through conversations with inhabitants from coastal villages, and through our own observations, that the tourism sector at Lake Urmia has almost completely disappeared. Abandoned tourist villages and semi-finished holiday homes adorning the former shoreline of the lake are a common sight, and many of those who used to work in tourism have either switched to agriculture or moved to larger cities in search of employment. These migrations have provoked both positive and negative effects: while remittances support household members remaining in the village, heavy outmigration affects the decay of infrastructure in and around formerly densely populated villages.

Agriculture is still an important employment sector in the region, but it has been hit particularly hard by the lake's desiccation, the general water crisis and climate change. Reports of fields affected by salt deposits, dry wells, extreme spring rains and long periods of drought, which negatively affect agricultural production, were frequently cited answers to the question on how the interlocutor perceived the Lake Urmia disaster. Against this backdrop, we are sceptical about the ULRP's goal of reducing water consumption in the agricultural sector by $40 \%$, as it will be difficult to implement, as it will have a significant impact on farmers and communities in the basin. The plan could even lead to serious social tensions; for instance, the suggestion to prohibit or limit unauthorised use of groundwater by local farmers would be met with some hostility. Additionally, as criticised by Shadkam et al. (2016), none of ULRP's intended water management plans were assessed under future climate change scenarios, which imply increasing temperatures, increasing evaporation and decreasing precipitation in the area. A key question for many farmers is whether and how alternative livelihoods and income sources that require less water can be promoted in the future. This means changing current farming practices (cultivation and irrigation), improving the economic value of current agricultural production through markets and seeking alternative sources of income. Appropriate policies and administrative structures are also needed to steer change towards the desired objectives. However, as already observed in the tourism sector, the further escalation of environmental degradation in the basin will likely result in more people ceasing farming and choosing to migrate, either temporarily or permanently, as their livelihoods and their economic and social well-being become further undermined. Although environmental change is an acknowledged driver of displacement and migration, it is typically only one of many interconnected drivers on which people base their decisions to migratesocio-economic, political, demographic, cultural and individual factors also play a role in this regard (UK Government Office for Science 2011; IOM 2014; Ionesco et al. 2016). However, at Lake Urmia, the environmental disaster is likely to influence further the migration decisions of vulnerable households or individuals (Khayyati and Aazami 2016; Maleki et al. 2018).

\section{Conclusion}

'Urmia', whose name derives from the Syriac-Aramaic words 'ur' (city) and 'mia' (water), literally means 'city by the water'. The progressive disappearance of the eponymous water body next to this city and the associated consequences of its drying are both, a severe social and environmental disaster. At the beginning of this article, we discussed how this socio-ecological disaster is the result of various human-induced processes, such as climate change, the construction of dams, the extension of irrigated farmland, excessive groundwater abstraction and increasing water demand in urban agglomerations.

The direct consequences of the lake's desiccation are diverse. Most notably, the systematic degradation of land and fresh water resources, negative effects on public health and food security, economic decline and unemployment create an increasingly more difficult socio-economic context for millions of villagers living in the basin's surrounding settlements. So far, the particular interplay between disastrous environmental change, socio-economic consequences and local adaptation or mitigation strategies of the local population have received scant investigation in the scientific literature.

With our article, we contribute to closing the scientific gap further. Recognising the current situation, by including people's opinions, identifying the main hazards and vulnerabilities of the situation is necessary to find proper solutions in the long run. One strength of our research is that through our fieldwork we have given a voice to people exposed to existential risk, i.e. those who have given us an individual 
description of their present situation in return, which goes beyond a general description of the consequences of the disaster. We have also outlined that the poor rural population in particular is currently facing great difficulties in adapting to changing living conditions. The once flourishing tourism at Lake Urmia is extinct, and so the strategy of many people who once worked in tourism has been to sell their property and to move to cities to find work. Others have tried to survive by switching to agriculture, putting further pressure on already overexploited water resources. As non-agricultural employment opportunities and job diversity are hampered, agriculture still continues to be the main source of employment for local villagers around Lake Urmia. During our research, it became clear that many people in this sector now face existential risks, as the sensitivity of agriculture to water stress and climate conditions make farmers vulnerable. While the ULRP aims to reduce water use in the Urmia basin, many farmers are already suffering as a result of persistent drought and dry wells. Their ability to adapt to changing conditions seems limited; however, modifying the cultivation of crops and looking for strategies to save water are of great importance to the region.

This paper has highlighted that it is necessary to find sustainable solutions as quickly as possible, to counter the environmental disaster and to create opportunities for the local population. However, many of the current efforts to restore the ecological balance of the lake have proven impractical or are hampered by financial constraints. The absence of an integrated approach and an implementable policy supporting the inclusion of both ecological and social facets in water management is prevalent.

In view of the fact that many of the world's end lakes (e.g. Aral Sea, Lake Chad or Lake Poopó in Bolivia) are on the point of drying up, Lake Urmia is a vivid example of how ecological and social systems are intertwined and how climate change and human influence can change the hydrology and ecosystem of an entire region, with subsequent unpredictable consequences for the population. Understanding the many complex causal connections, and developing sustainable resource governance, requires a multidisciplinary approach that includes scientific and social perspectives. The slow-onset disaster at Lake Urmia makes an ideal area for further research to study the many consequences of the disaster, their impacts on people living in rural settlements around the lake and individual adaptation strategies. Subsequent indications in this regard will prove constructive for adaptation or mitigation planning by stakeholders in other regions of Iran or the Middle East, where many water bodies are under water stress and where climate change will put further pressure on water availability.

Acknowledgements Open Access funding provided by Projekt DEAL. This research was made possible by the support of Augsburg University and our partners at Urmia University. We are particularly grateful to Dr. Nosrat Heidari and Monir Gholamzadeh Bazarbash M.A. for their technical assistance and valuable discussions during our field trips. We are looking forward to continuing our collaboration in the future.

Open Access This article is licensed under a Creative Commons Attribution 4.0 International License, which permits use, sharing, adaptation, distribution and reproduction in any medium or format, as long as you give appropriate credit to the original author(s) and the source, provide a link to the Creative Commons licence, and indicate if changes were made. The images or other third party material in this article are included in the article's Creative Commons licence, unless indicated otherwise in a credit line to the material. If material is not included in the article's Creative Commons licence and your intended use is not permitted by statutory regulation or exceeds the permitted use, you will need to obtain permission directly from the copyright holder. To view a copy of this licence, visit http://creativecommons.org/licenses/by/4.0/.

\section{References}

Agh, N. H. (2018). How to save Lake Urmia? Presentation held in the premises of ULRP (Urmia Lake Restoration Program) regional office. Urmia, October 2018.

Agha Kouchak, A., Norouzi, H., Madani, K., Mirchi, A., Azarderakhsh, M., Nazemi, A., et al. (2014). Aral Sea syndrome desiccates Lake Urmia: Call for action. Journal of Great Lakes Research, 41, 307-311.

Alipour, H., \& Olya, H. G. T. (2015). Sustainable planning model toward reviving Lake Urmia. International Journal of Water Resources Development, 31, 519-539.

Alizadeh-Choobari, O., Ahmadi-Givi, F., Mirzaei, N., \& Owlad, E. (2016). Climate change and anthropogenic impacts on the rapid shrinkage of Lake Urmia. International Journal of Climatology, 36, 4276-4286.

Alonso, E. J. (2017). Slow onset disasters: where climate change adaptation and disaster risk reduction meet. https://www. acclimatise.uk.com/2017/05/09/slow-onset-disasterswhere-climate-change-adaptation-and-disaster-riskreduction-meet/. Accessed October 31, 2019.

Anvari, A., \& Valaie, M. (2015). Evaluation of the effects of water level decline of Urmia Lake in sustainable rural development: Case study Central Marhamat Abad rural district, Miandoab County. Bulletin of Environment, Pharmacology and Life Sciences, 4, 65-71. 
Arkian, F., Nicholson, S. E., \& Ziaie, B. (2018). Meteorological factors affecting the sudden decline in Lake Urmia's water level. Theoretical and Applied Climatology, 131, 641-651.

Azizpour, F., Riahi, V., Tagiloo, A. A., \& Karimi, K. (2015). Disaster management and rural vulnerability (case study Urmia County). International Journal of Science Research, 6, 2136-2140.

Bavil, S., Zeinalzadeh, K., \& Hessari, B. (2018). The changes in the frequency of daily precipitation in Urmia Lake basin, Iran. Theoretical and Applied Climatology, 133, 205-214.

Chaudhari, S., Felfelani, F., Shin, S., \& Pokhrel, Y. (2018). Climate and anthropogenic contributions to the desiccation of the second largest saline lake in the twentieth century. Journal of Hydrology, 560, 342-353.

CIWP - Conservation of Iranian Wetlands Project (2016). Public Participation for Lake Urmia Restoration. https://www.un. org.ir/images/Publications/20161101wetlandslakeurmia1-en.pdf. Accessed October 10, 2019

Dalby, S., \& Moussavi, Z. (2017). Environmental security, geopolitics and the case of Lake Urmia's disappearance. Global Change, Peace \& Security, 29, 39-55.

Daryani, S. (2019). The eyes of Earth (Urmia Lake). https:// visura.co/daryani/stories/lake-urmia-iran-watercrisis . Accessed October 14, 2019

Delju, A. H., Ceylan, A., Piguet, E., \& Rebetez, M. (2013). Observed climate variability and change in Urmia Lake Basin, Iran. Theoretical and Applied Climatology, 111, 285-296.

Farhudy, A., \& Hajilou, B. (2012). Strategic evaluation of tourism industry development pattern with emphasis of ecotourism (Sample is Urmia Lake). In Proceedings of the international conference on Lake Urmia.

Fathian, F., Dehghan, Z., \& Eslamian, S. (2014). Analysis of water level changes in Lake Urmia based on data characteristics and non-parametric test. International Journal of Hydrology Science and Technology, 4(1), 18-38.

Financial Tribune Online (2017). Health Risks of Iran's Lake Urmia Desiccation Under Study. https://financialtribune. com/articles/people/57489/health-risks-of-irans-lakeurmia-desiccation-under-study. Accessed October 13, 2019.

Garousi, A. N., Samadi, A., Rasouli, K., \& Khanaliloo, B. (2013). Environmental crisis in Lake Urmia, Iran: A systematic review of causes, negative consequences and possible solutions (Unpublished).

Ghale, Y. A. G., Altunkaynak, A., \& Unal, A. (2017). Investigation anthropogenic impacts and climate factors on drying up of Urmia Lake using water budget and drought analysis. Water Resources Management, 32, 325-337.

Ghalibaf, M. B., \& Moussavi, Z. (2014). Development and environment in Urmia Lake of Iran. European Journal of Sustainable Development, 3(3), 219.

Gholampour, A., Nabizadeh, R., Hassanvand, M. S., Taghipour, H., Nazmara, S., \& Mahvi, A. H. (2015). Characterization of saline dust emission resulted from Urmia Lake drying. Journal of Environmental Health Science \& Engineering, 13(82), 1-11.

Girtler, R. (2001). Methoden der Feldforschung. Wien: Boehlau.

Hassanzadeh, E., Zarghami, M., \& Hassanzadeh, Y. (2012). Determining the main factors in declining the Urmia Lake level by using system dynamics modeling. Water Resources Management, 26, 129-145.

HRC - Human Rights Council. (2018). The slow onset effects of climate change and human rights protection for crossborder migrants. A/HRC/37/CRP.4.

IDMC - Internal Displacement Monitoring Centre. (2018). Synthesizing the state of knowledge to better understand displacement related to slow onset events. Task Force on Displacement Activity I.2. August 2018.

IEW - Iran Environmental and Wildlife Watch. (2018). "The water level», «extent» and «water volume available in the Lake. https://www.iew.ir/1396/10/19/57250. Accessed October 31, 2019.

Ilhan, A., \& Ayboga, E. (2012). Iran's dam policy and the case of the Lake Urumia. https://ekopotamya.net/index.php/ 2012/07/irans-dam-policyand-the-case-of-the-lake-urmia. Accessed May 25, 2018.

IOM. (2014). IOM outlook on migration, environment and climate change. Geneva: International Organization for Migration.

Ionesco, D., Mokhnacheva, D., \& Gemenne, F. (2016). The Atlas of environmental migration. London: Routledge.

IPCC - Intergovernmental Panel on Climate Change. (2014). Climate change 2014: Impacts, adaptation, and vulnerability. Part A: Global and sectoral aspects. Contribution of the Working Group II to the Fifth Assessment Report of the Intergovernmental Panel on Climate Change, New York.

Jalili, S., Hamidi, S. A., \& Ghanbari, R. N. (2016). Climate variability and anthropogenic effects on Lake Urmia water level fluctuations, Northwestern Iran. Hydrological Sciences Journal, 2, 1-11.

Jeihouni, M., Toomanian, A., Alavipanah, S. K., \& Hamzeh, S. (2017). Quantitative assessment of Urmia Lake water using spaceborne multisensor data and 3D modeling. Environmental Monitoring and Assessment, 189, 572.

Karbassi, A., Bidhendi, G. N., Pejman, A., \& Bidhendi, M. E. (2010). Environmental impacts of desalination on the ecology of Lake Urmia. Journal of Great Lakes Research, $36,419-424$.

Khayyati, M., \& Aazami, M. (2016). Drought impact assessment on rural livelihood systems in Iran. Ecological Indicators, 69, 850-858.

Khalyani, A. H., Mayer, A. L., \& Norman, E. S. (2014). Water flows toward power: Socioecological degradation of Lake Urmia, Iran. Society \& Natural Resources, 27, 759-767.

Khazaei, B., Khatami, S., Hamed Alemohammad, S., Rashidi, L., Wu, C., Madani, K., et al. (2019). Climatic or regionally induced by humans? Tracing hydro-climatic and land-use changes to better understand the Lake Urmia tragedy. Journal of Hydrology.

Madani, K. (2014). Water management in Iran: What is causing the looming crisis? Journal of Environmental Studies and Sciences, 4, 315-328.

Maleki, R., Nooripoor, M., Azadi, H., \& Lebailly, P. (2018). Vulnerability assessment of rural households to Urmia Lake drying (the case of Shabestar Region). Sustainability, 10, 1862.

Mardi, H. A., Khaghani, A., MacDonald, A. B., Nguyen, P., Karimi, N., Heidary, P., et al. (2018). The Lake Urmia environmental disaster in Iran. A look at aerosol pollution. The Science of the Total Environment, 633, 42-49. 
Marjani, A., \& Jamali, M. (2014). Role of exchange flow in salt water balance of Urmia Lake. Dynamics of Atmospheres and Oceans, 65, 1-16.

Matias, D. M. (2017). Slow onset climate change impacts. Global trends and the role of science-policy partnerships. Discussion Paper. Bonn: Deutsches Institut für Entwicklungspolitik.

Mehrian, M. R., Hernandez, R. P., Yavari, A. R., Faryadi, S., \& Salehi, E. (2016). Investigating the causality of changes in the landscape pattern of Lake Urmia basin, Iran using remote sensing and time series analysis. Environmental Monitoring and Assessment, 188, 462.

Mohammadi, A., Faraji, M., Conti, G. O., Ferrante, M., \& Miri, M. (2019). Mortality and morbidity due to exposure to particulate matter related to drying Urmia Lake in the NW Iran. European Journal of Internal Medicine, 60, e14-e15.

Mojarrad-Ashnaabad, M. (2013). Cost efficiency analysis of developing agriculture and drying Lake Urmia based on existing estimations. Forest and Rangeland, 98, 80-82.

Niayesh, U. (2018). Too late to save Middle East's largest saltwater lake, Urmia? https://en.trend.az/other/ commentary/2851439.html. Accessed May 24, 2018.

OECD - Organisation for Economic Co-operation and Development. (2001). Glossary of statistical terms: Ecological balance. https://stats.oecd.org/glossary/detail.asp?ID=713. Accessed May 23, 2018.

Ouria, M., \& Sevinc, H. (2016). The role of dams in drying up Lake Urmia and its environmental impacts on Azerbaijani Districts of Iran. Saussurea, 6, 54-65.

Pesyan, V. B., Porakrami, M., Mehrbani, B. F., \& Porakrami, S. (2017). The investigation of Lake Urmia drying trend and its important consequence on the surrounding settlements. Journal of Rural Research, 8, 438-453.

Pidgeon, N., \& Fischhoff, B. (2011). The role of social and decision sciences in communicating uncertain climate risks. Nature Climate Change, 1, 35-41. https://doi.org/10. 1038/nclimate1080.

Razmara, P., Massah Bavani, A. R., Motiee, H., Torabi, S., \& Lotfi, S. (2013). Investigating uncertainty of climate change effect on entering runoff to Urmia Lake Iran. $\mathrm{Hy}$ drology and Earth System Sciences Discussions, 10, 2183-2214.

Samadi, M. T., Khorsandi, H., Bahrami, A. F., Poorolajal, J., \& Tayebinia, H. (2019). Long-term exposures to Hypersaline particles associated with increased levels of Homocysteine and white blood cells. A case study among the village inhabitants around the semi-dried Lake Urmia. Ecotoxicology and Environmental Safety, 169, 631-639.

Sanikhani, H., Kisi, O., \& Amirataee, B. (2017). Impact of climate change on runoff in Lake Urmia basin, Iran. Theoretical and Applied Climatology, 132, 491-502.

Schmidt, M. (2018). Wasserkrise am Urmiasee im Iran: Eine Umwelt- und Sozialkatastrophe des Anthropozäns. Geographische Rundschau, 70(1/2), 38-43.

Shadkam, S., Ludwig, F., van Vliet, M. T. H., Pastor, A., \& Kabat, P. (2016). Preserving the world second largest hypersaline lake under future irrigation and climate change. The Science of the Total Environment, 559, $317-325$.

Sheikhi, M. (2018). Lake Urmia water level increases by $7 \mathrm{~cm}$. MEHR News Agency.
Sigaroodi, S. K., \& Ebrahimi, S. (2010). Effects of land use change on surface water regime (case study Orumieh Lake of Iran). Procedia Environmental Sciences, 2, 256-261.

Sima, S., \& Tajrishy, M. (2013). Using satellite data to extract volume-area-elevation relationships for Urmia Lake, Iran. Journal of Great Lakes Research, 39, 90-99.

Soudi, M., Ahmadi, H., Yasi, M., \& Hamidi, S. A. (2017). Sustainable restoration of the Urmia Lake: History, threats, opportunities and challenges. European Water, (60), 341-347.

Statistical Centre of Iran. (2016). Population by age groups and sex and province, the 2016 Population and Housing Census. https://www.amar.org.ir/english/Population-andHousing-Censuses. Accessed May 24, 2018.

Taheri, M., Emadzadeh, M., Gholizadeh, M., Tajrishi, M., Ahmadi, A., \& Moradi, M. (2019). Investigating the temporal and spatial variations of water consumption in Urmia Lake River Basin considering the climate and anthropogenic effects on the agriculture in the basin. Agricultural Water Management, 213, 782-791.

Talebi, T., Ramezani, E., Djamali, M., Lahijani, H. A. K., Naqinezhad, A., Alizadeh, K., et al. (2016). The LateHolocene climate change, vegetation dynamics, lake-level changes and anthropogenic impacts in the Lake Urmia region, NW Iran. Quaternary International, 408, 40-51.

Taravat, A., Rajaei, M., Emadodin, I., Hasheminejad, H., Mousavian, R., \& Biniyaz, E. (2016). A spaceborne multisensory, multitemporal approach to monitor water level and storage variations of lakes. Water, 8, 478 .

The Tehran Times. (2018). Lake Urmia likely to revive in 10 years; building our hopes up? https://www.tehrantimes. com/news/425530/Lake-Urmia-likely-to-revive-in-10years-building-our-hopes-up. Accessed May 20, 2019

Torabian, E. (2015). Exploring social vulnerability and environmental migration in Urmia Lake of Iran: Comparative insights from the Aral Sea. In F. Gemenne, Brücker, P., Ionesco, D. (Eds.), The state of environmental migration 2014: A review of 2013 (pp. 65-84). Geneva: IOM and Sciences Pro.

Tourian, M. J., Elmi, O., Chen, Q., Devaraju, B., Roohi, S., \& Sneeuw, N. (2015). A spaceborne multisensor approach to monitor the desiccation of Lake Urmia in Iran. Remote Sensing of Environment, 156, 349-360.

Toutakhaneh, M. A., Heydari Sareban, V., \& Mofarrah Bonab, M. (2018). Evaluating the effects of lake urmia's drought on resilience changes in rural settlements. Journal of Research \& Rural Planning, 6, 67-89.

UK Government Office for Science. (2011). Foresight: Migration and global environmental change: Future challenges and opportunities. Final Project Report. London: Government Office for Science.

ULRP - Urmia Lake Restoration Program. (2015). Urmia Lake restoration program. Brief Report and Projects Outline.

ULRP - Urmia Lake Restoration Program. (2017). Integrated programme for sustainable water resources management in Lake Urmia Basin. Project workplan, 29 November 2017.

UNFCCC - United Nations Framework Convention on Climate Change. (2012). Slow onset events. Technical paper.

UNEP, Geas - United Nations Environmental Programme, Global Environmental Alert Service. (2012). The drying of 
Iran's Lake Urmia and its environmental consequences. Environmental Development, 2, 128-137.

UNEP - United Nations Environmental Programme. (2017). Lake Urmia: Signs of recovery. https://wedocs.unep.org/ bitstream/handle/20.500.11822/22312/Foresight_\% 20Brief_\%20004_2017.pdf? sequence=1\&isAllowed=y. Accessed May 24, 2018.

USGS - United States Geological Service. (2019): LandLook Viewer. https://landlook.usgs.gov/viewer.html. Accessed November 20, 2019

Valizadeh, N., Bijani, M., Abbasi, E., \& Ganguly, S. (2018). The role of time perspective in predicting Iranian farmers' participatory-based water conservation attitude and behavior. Journal of Human Behavior in the Social Environment, 28, 992-1010.

Victor, D. G. (2015). Climate change: Embed the social sciences in climate policy. Nature, 520, 27-29.

Warner, K., Hamza, M., Oliver-Smith, A., Renaud, F., \& Julca, A. (2010). Climate change, environmental degradation and migration. Natural Hazards, 55, 689-715.
Worldbank. (2019). Population, total - Iran, Islamic Rep. I Data. https://data.worldbank.org/indicator/SP.POP. TOTL?locations=IR. Accessed October 31, 2019.

Yearley, S. (2009). Sociology and climate change after Kyoto: What roles for social science in understanding climate change? Current Sociology, 57, 389-405.

Zaman, R. M., Morid S., \& Delavar M., (2016). Evaluating climate adaptation strategies on agricultural production in the Siminehrud catchment and inflow into Lake Urmia, Iran using SWAT within an OECD framework. Agricultural Systems, 147, 98-110.

Zeinoddini, M., Bakhtiari, A., \& Ehteshami, M. (2015). Longterm impacts from damming and water level manipulation on flow and salinity regimes in Lake Urmia, Iran. Water and Environment Journal, 29, 71-87.

Publisher's Note Springer Nature remains neutral with regard to jurisdictional claims in published maps and institutional affiliations. 